\title{
Reformas Constitucionais e autonomia municipal no Brasil
}

\author{
Angela Moulin S. Penalva Santos* \\ Liana Portilho Mattos**
}

\begin{abstract}
The municipality in Brazil became a federative entity after the Federal Constitution of 1988, within the context of redemocratisation of the power structures, which included the extension of the citizens' rights. In this way, the municipal governments became important actors in these policies, having an effect on the relationships between central and local governments, particularly in matters of tax distribution. The increase in financial autonomy of the municipalities diminished the contributions appropriated by the central government, which faced increasing financial obligations due to the extension of the social rights that were introduced by the current Constitution. These facts led the central government to introduce amendments to the Constitution which included an increased taxation not shared with the state and local governments, as well as a transfer of responsibilities, and a greater financial participation, in the public policies.
\end{abstract}

Keywords: municipality, federalism, decentralisation.

\section{Resumo}

O Município tornou-se ente federativo após a Constituição Federal de 1988, num contexto de redemocratização das estruturas de poder no Brasil, o que incluiu a ampliação dos direitos dos cidadãos. Assim, os governos municipais tornaram-se importantes atores destas políticas, com impactos nas relações entre o governo central e os locais, especialmente no que tange à distribuição da arrecadação tributária. $\mathrm{O}$ aumento da autonomia financeira dos Municípios diminuiu a parcela das receitas apropriadas pelo governo central, que enfrentava crescentes obrigações financeiras diante da ampliação dos direitos sociais introduzidos pela atual Constituição. Essa evidência o levou a reagir com emendas à Constituição que levaram à ampliação da carga tributária não-partilhada com os governos estaduais e municipais, bem como com a transferência de responsabilidades - e maior participação no financiamento - de políticas públicas.

Palavras clave: município, federalismo, descentralização.

*Universidade do Estado do Rio de Janeiro. Correo-e: angelapenalva@terra.com.br.

** Pontifícia Universidade Católica de Minas Gerais. Correo-e: lianaportilho@ terra.com.br. 


\section{Introdução}

A partir da Constituição de 1988, o Município brasileiro, até então simples parte integrante do Estado-Membro, foi alçado à condição de ente federado, passando a ser personagem autônomo do denominado Pacto Federativo. Em razão disso, é certo que a realidade do Município sofreu grandes modificações, decorrentes de seu inédito papel no novo padrão de organização federativa que a Constituição implantou. Essas modificações configuraram-se, principalmente, nas mudanças ocorridas na distribuição dos recursos tributários e também no processo de descentralização das políticas públicas, que conferiu ao Município novas responsabilidades político-administrativas.

A despeito da concepção formulada pelo constituinte originário, decorridos quase 15 anos, é possível verificar que o modelo de Federação pensado em 1988 não corresponde ao que se desenha na Carta atual, reformada mais de 40 vezes desde então.

Este trabalho tem por objetivo analisar o impacto das sucessivas reformas à Constituição de 1988 na autonomia dos Municípios. Na primeira parte, serão apresentadas algumas das especificidades da autonomia do ente municipal e do pacto federativo no Brasil. $\mathrm{Na}$ segunda, serão analisadas algumas das principais emendas constitucionais, para identificar os seus possíveis reflexos na autonomia dos Municípios brasileiros. Na terceira e última, serão feitas considerações finais sobre os pontos principais do trabalho.

A hipótese estudada refere-se à improcedência das críticas ao alegado "excessivo descentralismo financeiro" da Constituição Federal em face da expansão dos direitos dos cidadãos brasileiros, demandando forte aporte de recursos públicos. Ao completar 15 anos de vigência, a "Constituição Cidadã" voltou a ser acusada de gerar ingovernabilidade, seja porque não previa recursos necessários para dar efetividade à cidadania ampliada, seja porque alçava o Município à condição de ente autônomo da Federação, introduzindo maior rigidez na negociação do pacto federativo.

Este estudo está baseado no levantamento das Emendas à Constituição e na identificação das que afetam a autonomia municipal pactuada em 1988. Já foram aprovadas 40 emendas constitucionais, ${ }^{1}$ sendo apenas a última no Governo Lula (2003). As

\footnotetext{
${ }^{1}$ Entraram em vigor, após o término deste artigo, as Emendas 41 (Reforma Previdenciária) e 42 (Reforma Tributária), ambas em 19/12/2003.
} 
demais são, em sua quase totalidade, do período referente aos dois mandatos do presidente Cardoso (1995-1998 e 1998-2002). As exceções referem-se às primeiras Emendas que entraram em vigor ainda no governo Itamar Franco (1993-94), quando Cardoso era ministro da Fazenda. Assim, a reforma constitucional realizada no Brasil está profundamente identificada com as iniciativas de Cardoso.

\section{Constituição, Município e pacto federativo}

Embora seja correto afirmar, à luz da Constituição, que no Brasil existe um pacto federativo formado por União, Estados, Distrito Federal e Municípios, na verdade tal afirmação deve ser vista com crítica e reserva. É que no Brasil nunca se estabeleceu um pacto, mas apenas um simples arranjo federativo, feito às avessas dos modelos pensados e consagrados na experiência de outros países. Nos Estados Unidos e na Suíça, por exemplo, regiões autônomas decidiram juntar-se para formar a Federação, abrindo mão de sua soberania e celebrando um pacto de verdade que nasceu de baixo para cima. Aqui, ocorreu uma inversão - ou invenção - que em nada correspondia ao modelo federativo tradicional: os Estados foram criados e "ganharam" uma autonomia que não tinham, ao passo que as instâncias municipais, que já existiam, foram deixadas de fora da Federação, em patamar inferior ao dos Estados e sem autonomia.

Duas idéias são centrais para compreender o significado, o propósito e o sucesso na formação de uma Federação: a de autonomia e a de participação (Bonavides, 1997: 181 et seq.).

Em relação à primeira, a Constituição de 1988 assegurou ao Município quatro capacidades: a) de auto-organização, por meio de uma Lei Orgânica elaborada e promulgada por sua Câmara de Vereadores, sem interferência de qualquer espécie do Legislativo Estadual ou Federal; $b$ ) de autogoverno, exercida pelo prefeito e vereadores eleitos pelo voto direto e secreto (desapareceu, de vez, a figura do prefeito nomeado); c) de autolegislação sobre assuntos de interesse local (não mais sobre "assuntos de peculiar interesse") e sobre outros, de forma suplementar e concorrente; e d) de auto-administração, para arrecadar os tributos de sua competência, aplicar suas receitas e prestar serviços públicos à comunidade local. 
Não há como negar, então, que o sistema federativo adotado pelo Brasil desde a Proclamação da República evoluiu significativamente, ficando o Município equiparado ao Estado-Membro, dotado, como este, de autonomia - política, administrativa e financeira - e de competências próprias.

Entretanto, em relação à idéia central da participação, a situação do ente municipal é bem outra. Primeiro, é necessário esclarecer que tal participação é tomada no sentido de valoração da vontade política de todos os entes federados na construção da soberania da Federação, mas também no sentido de cooperação e ampliação da autonomia entre tais entes, autonomia obtida mediante uma repartição constitucional de competências que leve em conta a mesma vontade de todos os entes na sua formação. ${ }^{2}$

$\mathrm{Na}$ verdade, a repartição de competências na Constituição de 1988, embora tenha sofrido uma grande influência de associações e entidades que defendiam a causa municipalista, não foi determinada levando em conta a participação política dos Municípios, mesmo porque eles inexistiam formalmente para a Federação até então. ${ }^{3}$ Talvez aqui resida uma das causas que têm levado, tradicionalmente, a União ao centralismo nas tomadas de decisão que afetam todos os entes, especialmente as que surtem efeitos sobre a chamada autonomia financeira dos Municípios. Para ilustrar, o projeto de reforma tributária atualmente em tramitação no Congresso $\mathrm{Nacional}^{4}$ é exemplo da pouca ou da quase nula participação dos Municípios nas discussões anteriores ao envio do projeto e, ao mesmo tempo, acerca do centralismo antes mencionado, da crescente participação dos Estados nessas discussões.

Nesse sentido, quanto à autonomia financeira dos Municípios no contexto do pacto federativo, é possível afirmar que o novo modelo de Federação incorporou, em termos, as idéias que recomendaram, por um lado, a transferência de encargos da União para os Estados e os Municípios e, por outro, a desconcentração

${ }^{2}$ De acordo com Bonavides (1997: 181), “[...] Tanto a participação como a autonomia existem em função das regras constitucionais supremas, que permitem ver na Federação, como viu Tocqueville no século XIX, duas sociedades distintas, encaixadas uma na outra, a saber, o Estado federal e os Estados federados harmonicamente superpostos e conexos".

${ }^{3}$ É importante destacar que a repartição de competências na Constituição de 1988 tem outras características negativas, como afirma Eduardo Kugelmas (2001: 37): "Uma das características do modelo federativo brasileiro é o grande número de competências conjuntas dos três níveis, sem uma definição clara das respectivas esferas”.

${ }^{4}$ Esse projeto foi dividido em três etapas, a primeira das quais foi aprovada como Emenda Constitucional 42, em 19/12/2003. 
dos recursos tributários, com alterações nos critérios de sua repartição. Tal modelo deixou claro que o Município, no desempenho de suas atribuições exclusivas, não deveria nem poderia subordinar-se ao Estado-Membro ou à União, e que as leis municipais deveriam prevalecer sobre as estaduais e as federais, e até mesmo sobre a Constituição do Estado, em caso de conflito.

Diante de tudo isso, parece correto dizer que o Município brasileiro, com a Constituição de 1988, adquiriu - teoricamente o direito de exercer a condição de ente federado. Na prática, contudo, o exercício pleno desse direito não lhe foi garantido. $\mathrm{O}$ constituinte de 1988 parece ter imaginado que haveria uma adesão automática dos governantes aos seus propósitos descentralizadores, que entretanto não ocorreu.

Dificultando a viabilidade do processo de autonomia financeira municipal, esta passou a ser atacada por reduzir as receitas do governo central: a participação da União na receita disponível no país diminuiu de 61.1\%, em 1989, para 56.4\%, em 1996, o que não poderia ter deixado de acontecer, posto que a participação dos Estados e Municípios nessa mesma receita e nesse mesmo período cresceu, respectivamente, de $25 \%$ para $27 \%$ e de 13.9\% para 16.7\% (Kugelmas, 2001: 36). Após uma reação do governo central, houve uma recomposição das receitas disponíveis da União, que passaram a 57.78\%, ficando os Municípios com 16.62\%, em 2002 (BNDES, 2003). É importante destacar que a participação dos Municípios somente foi mantida nesse patamar devido às transferências do Sistema Único de Saúde (sus), consideradas transferências voluntárias, "dinheiro carimbado", distintas das de natureza constitucional, sobre as quais o Município tem inteira autonomia em sua alocação.

Diante desse fato, agravado porque verificado num contexto de instabilidade política, de ameaça de hiperinflação e de uma aguda crise da dívida externa, iniciou-se uma verdadeira batalha entre a União, os Estados-Membros e os Municípios, em que a busca do equilíbrio fiscal fora a justificativa para o embate que então se travou e que continua sendo travado, interferindo, séria e negativamente, na autonomia dos entes subnacionais.

O Governo Federal jamais se conformou com os avanços obtidos, em 1988, pelos Estados-Membros e Municípios e não conseguiu conviver com o novo modelo de Federação. Para a União, avanços institucionais dos Estados e Municípios - tidos como "ganhos" deles - foram vistos como "perdas" inaceitáveis. 
Analisando a conjuntura política e constitucional a partir de 1988, parece irrefutável a idéia de que a União tratou de combater os "ganhos" dos entes subnacionais para tentar eliminar as "perdas", tomando como alvo preferencial dessa disputa inglória o sistema tributário brasileiro.

Do lado da receita, o Governo Federal passou a compensar as suas "perdas" recorrendo à criação de tributos e à elevação das alíquotas dos já existentes, seguindo uma lógica inteligente e perversa de maximização de resultados: as escolhas feitas com essa intenção passaram a recair prioritariamente em tributos não partilhados com os Estados e os Municípios, como as denominadas contribuições sociais, entre as quais a Contribuição para o Financiamento da Seguridade Social (Cofins) e a Contribuição Provisória sobre Movimentação Financeira (CPMF).

Do lado da despesa, o Governo Federal deu início a uma política destinada à limitação das funções do Estado, estimulando o processo de descentralização, entendido como transferência de responsabilidades do governo central às esferas subnacionais. A União passou a se concentrar nas políticas macroeconômicas e transferiu as políticas sociais para Estados e Municípios, especialmente a execução dos serviços que são obrigação constitucional do poder público e direito dos cidadãos.

Ao eleger a descentralização das políticas públicas uma prioridade, a União mostrava sintonia com o espírito dos constituintes de 1988. No entanto, ao promover a expansão da agenda dos governos locais, inclusive mediante o recurso de vinculação das receitas municipais, o governo central ampliou as necessidades financeiras dos Municípios, mas conteve a elevação das transferências intergovernamentais ao recompor suas receitas com recursos não-partilháveis com Estados e Municípios.

Foram e vêm sendo muitas as pressões do Executivo Federal sobre o Congresso, envolvendo barganhas, para que os interesses da União prevaleçam. Nesse contexto, um dos mecanismos utilizados de maneira bastante eficaz para que a União conseguisse recompor parte do poder perdido em 1988 foi a prática do "remendo" à Constituição de 1988, totalmente desfigurada, diversas vezes, por emendas impostas pela sanha fiscal, centralizadora e autoritária da União, ${ }^{5}$ que põe em xeque o arranjo federativo pactuado em 1988 .

\footnotetext{
${ }^{5}$ Expressão de Joel de Menezes Niebuhr no prefácio a Vedana (2002).
} 
A Constituição, na verdade, previa uma revisão após cinco anos de vigência. Em 1993, contudo, a situação política do país, sob o governo de Itamar Franco, eleito vice-presidente nas eleições de 1989, estava muito fragilizada devido ao processo de impedimento do presidente Collor, ocorrido em setembro do ano anterior. Ademais, o Congresso também enfrentava uma crise de credibilidade deflagrada com o "escândalo do orçamento". ${ }^{6}$ Nessas condições, malogrou a tentativa de revisão constitucional. Somente após a posse do presidente Fernando Henrique Cardoso, em 1995, seria iniciada a reforma constitucional por meio do recurso às emendas constitucionais (Mello, 2002).

\section{Constituição e reformas}

\subsection{Situando o problema}

Nesses 15 anos de vigência da "Constituição Cidadã", 40 emendas constitucionais alteraram-na significativamente. Tamanha sanha mudancista deve ser considerada no contexto histórico em que foi elaborada a Carta Magna.

A quebra de ordem democrática pelo regime militar (19641985) foi acompanhada da introdução de uma Constituição que concentrava o poder em torno da União, inclusive mediante centralização da arrecadação tributária. Apesar disso, foi mantido, e até ampliado, o sistema de transferência de receitas para os governos estaduais e municipais. Entretanto, tais recursos estavam, em grande parte, vinculados a programas definidos pelo planejamento do governo central. Tratava-se de "dinheiro carimbado" que não poderia financiar projetos eventualmente mais necessários segundo os critérios das esferas subnacionais de governo. Os Municípios eram inteiramente dependentes da tutela dos Estados, mas os governadores, não obstante serem entes autônomos da Federação, viajavam regularmente a Brasília para buscar recursos, num ritual que a imprensa denominou de "política de pires na mão”.

A crise econômica deflagrada a partir de fins dos anos 1970 reduziria a capacidade financeira da União de cooptar os gover-

\footnotetext{
${ }^{6}$ Escândalo provocado pela descoberta de um esquema que associava parlamentares e técnicos do Congresso Nacional para manipular o Orçamento Federal.

7 A Constituição Federal foi chamada de "Constituição Cidadã" pelo então presidente do Congresso Nacional, deputado Ulysses Guimarães, no ato de sua promulgação, em 5 de outubro de 1988, por ter ampliado significativamente os direitos sociais dos cidadãos brasileiros.
} 
nos estaduais. Essa perda de controle ficaria ainda mais acentuada após a retomada da autonomia política dos governadores, que voltaram a ser eleitos por voto popular e direto em 1982. Três anos depois, foi a vez dos Municípios capitais dos Estados elegerem diretamente seus prefeitos. A legitimidade do voto popular, associada à perda de capacidade financeira da União, resultaram num movimento pela redemocratização das estruturas de poder que culminaria com a elevação dos Municípios “às galas da Constituição" em $1988 .{ }^{8}$

\subsection{Emendas Constitucionais: o efeito sobre a autonomia dos Municípios}

Antes mesmo de a Constituição ter completado seu quinto aniversário, a Emenda 3, de 18 de março de 1993, já alterara praticamente toda a Seção v do Capítulo I do seu Título vi, que trata dos impostos dos Municípios, extinguindo, por exemplo, o que incidia sobre as vendas a varejo de combustíveis líquidos e gasosos, exceto óleo diesel - de fácil cobrança, que muito Município brasileiro nem chegara a instituir, ainda -, e revogando o dispositivo que permitia a progressividade, no tempo, do imposto sobre a propriedade predial e territorial urbana, para assegurar o cumprimento da função social da propriedade. ${ }^{9}$

Logo depois, a Emenda Constitucional de Revisão 1 , de $1^{\circ}$ de março de 1994, instituiu - com o confessado objetivo de sanear as finanças da Fazenda Pública Federal e de estabilizar a Economia o Fundo Social de Emergência (FSE), que limitou drasticamente as transferências vinculadas da União para os Estados e Municípios. De acordo com Kugelmas (2001: 3), a aprovação do FSE, que restringe o volume das transferências vinculadas a Estados e Municípios, foi conseguida

a duras penas e explica-se pelo temor da explosão inflacionária e por seu caráter transitório (o texto referia-se apenas aos anos de 1994 e 1995). Considerada vital para dar credibilidade fiscal ao plano de estabilização [Plano Real], esta medida foi a primeira reversão na trajetória descentralizadora que se iniciara nos últimos anos do regime militar.

Esse Fundo, que seria transitório, foi depois prorrogado, renomeado e reforçado, não sendo razoável acreditar que as trans-

\footnotetext{
${ }^{8}$ Segundo expressão de Ricardo Lira (1996), ao comentar a nova condição dos Municípios como entes autônomos da Federação.

${ }^{9}$ Isso seria revertido mais tarde, com a Emenda Constitucional 29.
} 
ferências por ele limitadas voltem algum dia a ser como eram, quando o constituinte de 88 as instituiu.

Essa mesma Emenda Constitucional de Revisão 1 revogou, expressamente, o $\mathbb{4} 4^{\circ}$ do art. $2^{\circ}$ da Emenda Constitucional 3, de 1993, em que se destinava ao custeio de programas de habitação popular vinte por cento do imposto sobre movimentação ou transmissão de valores e de créditos e direitos de natureza financeira que a União ficara autorizada a instituir, imposto esse que por certo interessava, e muito, aos Municípios.

Nesse mesmo sentido, a Emenda Constitucional 10, de 4 de março de 1996, "re-instituiu" (prorrogou) o Fundo Social de Emergência, com a denominação de Fundo de Estabilização Fiscal, fazendo desaparecer, assim, a emergência, mas mantendo e ampliando as limitações ou os contingenciamentos das transferências vinculadas da União aos Estados e Municípios, em prejuízo destes. Outra vez, a União viu compensadas suas "perdas", com a redução dos "ganhos" dos demais entes da Federação.

A Emenda Constitucional 12, de 15 de agosto de 1996, permitiu à União estabelecer contribuição provisória sobre movimentação ou transmissão de valores e de créditos e direitos de natureza financeira (CPMF), cuja alíquota não excederia a vinte e cinco centésimos por cento (podendo ser reduzida pelo Executivo), seria destinada integralmente ao Fundo Nacional de Saúde, para financiamento das ações e serviços de saúde, e não poderia ser cobrada por prazo superior a dois anos. A CPMF, hoje se sabe, foi (é), na verdade, um imposto federal não-transferível, disfarçado de contribuição social, que de "provisória" só tem (teve) o nome e cuja destinação ("salvar a saúde") nunca foi respeitada, pois os recursos de sua arrecadação serviram, sempre, para cobrir despesas financeiras no orçamento da União. Além disso, com a CPMF, legalizou-se, no Brasil, a bitributação, uma vez que ela incide sobre o pagamento, pela via bancária, de qualquer tributo municipal, estadual ou federal, o que se torna mais sério na medida em que o Município e o Estado-Membro acabam, de certa forma, tributados pela União (quando se paga um imposto municipal ou estadual, o dinheiro pago deixa de ser do contribuinte e passa a ser do ente federado, logo, a CPMF cobrada no momento do pagamento é, na verdade, um adicional cobrado pela União sobre uma renda do Município ou dos Estados).

Outra emenda que merece ser analisada é a Emenda Constitucional 14, de 12 de setembro de 1996, que estabeleceu novas e maiores obrigações do Município para com o ensino e autorizou 
a União a criar o Fundo de Manutenção e Desenvolvimento do Ensino Fundamental e de Valorização do Magistério (Fundef), de natureza contábil (de fato, criado, posteriormente, por lei). Trata-se do programa de maior capilaridade na Federação brasileira, somente comparável ao do Sistema Único da Saúde, seja pela abrangência nacional, seja pela importância dos recursos mobilizados.

O Fundef beneficiou, mais uma vez, a União, que não respeitou os critérios estabelecidos em lei para a distribuição proporcional dos seus recursos e para sua fiscalização e controle, bem como a fórmula de cálculo do valor mínimo nacional por aluno. Em nome desse Fundo, a União transferiu competências para os Estados-Membros, e estes, da mesma forma, "municipalizaram”, à força, suas escolas, ficando o Município com escolas de mais e recursos de menos, sem saber se estavam, ou não - e com certeza estavam -, sendo atacados em sua autonomia financeira, uma vez que a lógica do Fundo é altamente complexa.

Vejamos, de forma mais detalhada, o problema: a Constituição de 1988 havia estipulado, no art. 60 do Ato das Disposições Constitucionais Transitórias, que o poder público, nos dez anos seguintes, aplicaria pelo menos cinqüenta por cento dos recursos a que se referia o art. 212 da Carta para eliminar o analfabetismo e universalizar o ensino fundamental.

O mencionado art. 212, por seu turno, afiança que "a União aplicará, anualmente, nunca menos de dezoito, e os Estados, o Distrito Federal e os Municípios, vinte e cinco por cento da receita resultante de impostos, compreendida a proveniente de transferências, na manutenção e desenvolvimento do ensino".

Os recursos provenientes das transferências de que trata o referido dispositivo, no que tange ao Município, estão previstos nos arts. 158, II, e 159, I, “a”.

No entanto, essa situação jurídica perdurou apenas no período entre a promulgação da Constituição e o advento da Emenda Constitucional 14, de 12 de setembro de 1996, que modificou os arts. 34, 208, 211 e 212 do texto da Carta e em particular o art. 60 do Ato das Disposições Constitucionais Transitórias, prorrogando por mais dez anos, a contar da promulgação da Emenda, o prazo inicialmente previsto naquele artigo (que expiraria em 1998) e alterando e ampliando, ainda, o percentual e a destinação dos recursos a que se refere o art. 212 (antes, deveriam ser aplicados cinqüenta por cento, no mínimo, daqueles recursos, para eliminar o analfabetismo e universalizar o ensino fun- 
damental; depois, essa aplicação passou a ser de obrigatórios sessenta por cento, visando à manutenção e ao desenvolvimento do ensino fundamental, com o objetivo de assegurar a universalização de seu atendimento e a remuneração condigna do magistério).

A par disso - como já se viu -, a referida Emenda autorizou a União a criar o Fundef, estipulando que ele seria constituído por, pelo menos, quinze por cento dos recursos a que se referem os arts. 155, II; 158, Iv; 159, I, “a” e "b”, e II, da Constituição, determinando que os valores relativos ao referido Fundo seriam distribuídos entre cada Estado e seus Municípios proporcionalmente ao número de alunos matriculados nas respectivas redes de ensino fundamental e que a União Federal complementaria os recursos dos Fundos em cada Estado e no Distrito Federal, quando seu valor por aluno não alcançasse o mínimo definido nacionalmente.

Por fim, a Emenda estipulou que a lei ordinária disporia acerca da organização dos Fundos, da distribuição proporcional dos seus recursos, de sua fiscalização e controle, bem como da forma de cálculo do valor mínimo nacional por aluno. Pela Lei 9.424, de 24 de dezembro de 1996, foi então implantado, de fato, o Fundef, na qual se estabelecia que a partir de $1^{\circ}$ de janeiro de 1998 o referido Fundo seria criado, automaticamente, no âmbito de cada Estado.

A mencionada Lei 9.424/96, ao dispor sobre a forma de cálculo do valor mínimo nacional por aluno, determinou que tal valor seria fixado por ato do presidente da República e nunca seria inferior à razão entre a previsão da receita total para o Fundo e o número total de matrículas do ensino fundamental no ano anterior, acrescido do número total estimado de novas matrículas.

Foi dessa forma que surgiu o Fundef, que obrigou o Município a contribuir com seus parcos recursos, para uma conta única, de natureza contábil, pelos dez anos subseqüentes, da qual aqueles recursos seriam recambiados para seus legítimos donos, após uma distribuição proporcional ao número de alunos nas respectivas redes de ensino fundamental.

Ocorre que a Emenda Constitucional 14/96 afrontou, entre outros dispositivos da Constituição, o do art. $60, \mathbb{\$} 4^{\circ}$, I, que diz não poder ser objeto de deliberação a proposta de emenda tendente a abolir a forma federativa de Estado.

A Emenda simplesmente ignorou a condição de ente federado do Município e a sua conseqüente autonomia financeira, que advém das receitas determinadas no texto constitucional, entre as 
quais as provenientes da arrecadação dos tributos de sua competência e as decorrentes da repartição dos impostos federais e estaduais.

É fora de dúvida, portanto, que a Emenda Constitucional 14/ 96 feriu a autonomia do Município, posto que fez evaporar, antes mesmo de chegar em seus cofres, parte dos recursos que, pela Constituição, deveriam ser-lhe integralmente destinados.

Não bastasse tudo isso, a Constituição foi novamente emendada para embaraçar mais ainda a autonomia do Município.

Em 12 de setembro de 1996, pela Emenda 15, estabeleceu-se que Lei Complementar Federal determinaria o período no qual a lei estadual procederia à criação, à incorporação, à fusão e ao desmembramento de Municípios, que dependeriam de consulta prévia, mediante plebiscito, às populações dos Municípios envolvidos, após a realização de Estudos de Viabilidade Econômica apresentados e publicados na forma da lei (federal, por certo). Observe-se que a Constituição havia deixado a União de fora dessa questão, não prevendo Lei Complementar Federal nem o Estudo de Viabilidade Econômica.

Houve, de fato uma proliferação de Municípios, mas o remédio para esse mal não é, com certeza, a intromissão da União. A criação de muitos novos Municípios foi resultado dos procedimentos previstos pela Constituição de 1988, facilitando a emancipação de distritos, que se tornaram Municípios: era necessário ouvir em plebiscito apenas a população da área a ser emancipada.

A maior parte dos novos Municípios, assim como a maior parte dos Municípios já existentes, tem sua receita municipal muito dependente das receitas de transferências, em particular do Fundo de Participação dos Municípios (FPM). Este é constituído de $22.5 \%$ do somatório dos impostos sobre produtos industrializados e de renda. O critério de distribuição do FPM ${ }^{10}$ é diretamente proporcional à população municipal e inversamente proporcional à sua renda per capita.

Trata-se de uma fonte de receita municipal com viés redistributivista que favorece os Municípios de pequeno porte localizados em regiões menos dinâmicas. Nessas condições, e sem que tenha havido aumento da arrecadação dos impostos que compõem o FPM, o aumento no número de Municípios produz uma

${ }^{10}$ Segundo a Lei Complementar 63/1989, o FPM será assim distribuído entre os Municípios: $10 \%$ entre as capitais estaduais, 3.6\% entre os Municípios com mais de 156,216 habitantes e os $86.4 \%$ restantes entre os demais Municípios, aí incluídos aqueles com população superior a 156,216 habitantes. 
perda de receita nos já instalados. Os novos Municípios recémemancipados, por outro lado, garantem uma receita que antes da emancipação era alocada sistematicamente na sede do Município ao qual o distrito pertencia.

Outra crítica à criação dos aproximadamente 1,000 Municípios nos últimos 15 anos refere-se ao aumento dos gastos relacionados à instalação nesses novos Municípios dos poderes executivo e legislativo e do quadro de pessoal administrativo. Essa seria uma forma menos eficiente de alocar recursos públicos do que seria a realização de investimentos. Cabe lembrar, todavia, que, embora ineficiente, essa foi uma maneira de redistribuir recursos para localidades não beneficiadas pelos investimentos públicos municipais antes da emancipação dos distritos.

No mesmo passo, rumo à reconcentração dos poderes distribuídos em 1988, a Emenda Constitucional 17, de 22 de novembro de 1997, estendeu o prazo de validade do Fundo de Estabilização Fiscal; a Emenda 21, de 18 de março de 1999, prorrogou a CPMF; e a Emenda 25, de 14 de fevereiro de 2000, alterou os limites de despesas do Município com o seu Poder Legislativo. Todas essas Emendas, de um modo ou de outro, afetam a autonomia dos Municípios brasileiros.

Em seguida, veio a Emenda 26, de 14 de fevereiro de 2000, que tornou a moradia direito social, incluindo-a no rol dos direitos sociais fundamentais previstos no art. $6^{\circ}$ da Carta. Tal Emenda não representou, por si, uma ingerência na autonomia municipal, na medida em que já figurava no texto de 1988 a competência comum da União, dos Estados, do Distrito Federal e dos Municípios em "promover programas de construção de moradias e a melhoria das condições habitacionais e de saneamento básico" (art. 23, IX).

No entanto, assim que o direito à moradia passa a ter status de direito fundamental, a sua prestação passa a ser exigível pelo cidadão de imediato, por força do disposto no art. $5^{\circ}, \mathbb{S} 1^{\circ}$, da Constituição: "as normas definidoras de direitos e garantias fundamentais têm aplicação imediata”. Portanto, em tese, o Município tem de desempenhar a competência estabelecida no art. 23, Ix, num grau muito mais elevado de necessidade e responsabilidade. ${ }^{11}$

Posteriormente, outras emendas constitucionais "anti-autonomia municipal” foram promulgadas. A Emenda 27, de 21 de março de 2000, desvinculou “de órgão, fundo ou despesa, no período

${ }^{11}$ Cf. Emenda de Revisão 1. 
de 2000 a 2003, vinte por cento da arrecadação de impostos e contribuições sociais da União, já instituídos ou que vierem a ser criados no referido período, seus adicionais e respectivos acréscimos legais", sem reduzir "a base de cálculo das transferências a Estados, Distrito Federal e Municípios". A chamada Desvinculação das Receitas da União (DRU) veio confirmar uma prática iniciada em 1994, com a Emenda de Revisão 1, quando a criação do já mencionado Fundo Social de Emergência proporcionava alguma flexibilidade ao orçamento da União. Essa estratégia, no entanto, foi implementada em detrimento da autonomia municipal - e também estadual - pactuada pelo constituinte de 1988.

De significativa importância em muitos sentidos foi a entrada em vigor da Emenda 29, de 13 de setembro de 2000, que alterou diversos artigos da Constituição, impondo restrições e condições para a aplicação de recursos para financiamento das ações e serviços públicos de saúde, por parte dos Estados, do Distrito Federal e dos Municípios. Essa Emenda criou uma vinculação das receitas dos governos municipais com a assistência à saúde, na proporção de $15 \%$ de suas receitas correntes. Tal vinculação certamente fere a autonomia municipal em relação à destinação dada a parte da sua arrecadação tributária própria e das receitas de transferências constitucionais, ambas receitas que a Constituição Federal assegura serem do Município, ao qual cabe administrálas segundo o interesse local.

Em contrapartida a tal ingerência na autonomia municipal, a União introduziu nessa mesma Emenda 29 um artigo que tornou constitucional a progressividade na cobrança do Imposto Predial e Territorial Urbano (IPTU), imposto de competência municipal. Apesar de já previsto na Constituição, o IPTU progressivo vinha sendo considerado bitributação e, portanto, inconstitucional, o que inviabilizava a sua cobrança pelos Municípios. Por isso, o dispositivo que possibilitou aos Municípios impor a progressividade na cobrança do IPTU foi apresentado como uma compensação aos Municípios, que passaram a ter seu orçamento comprometido com a criada vinculação aos serviços de saúde.

No mesmo ano de 2000, a Constituição voltou a ser emendada: a Emenda 31, de 14 de dezembro de 2000, instituiu, no âmbito do Poder Executivo Federal, para vigorar até o ano de 2010, o Fundo de Combate e Erradicação da Pobreza, destinando-lhe recursos que, mais uma vez, reduziram as transferências da União para os Estados e Municípios. Ademais, essas duas esferas subnacionais de governo "devem instituir fundos de combate à po- 
breza", sendo que os Municípios poderão criar adicional de meio ponto percentual na alíquota do Imposto sobre Serviços (ISS), imposto de competência municipal, cuja administração é de responsabilidade exclusiva do Município.

A Emenda 33, de 11/12/2001, alterou o sistema tributário nacional ao criar a Contribuição de Intervenção no Domínio Econômico (CIDE), incidente sobre combustíveis. Como a CPMF, anteriormente mencionada, é um tributo que beneficia tão-somente a União, uma vez que, por ser contribuição, não é partilhado com os demais entes governamentais.

Outra emenda relevante à análise aqui empreendida é a Emenda 37, de 12 de junho de 2002, que, entre outras disposições, prorrogou o prazo de cobrança da CPMF. São dois os pontos a serem destacados. O primeiro refere-se ao fato de que a CPMF, cujos recursos deveriam financiar apenas a Saúde, passou a financiar também a Previdência e o Fundo de Combate à Pobreza. $\mathrm{O}$ aspecto central no que tange à autonomia financeira dos $\mathrm{Mu}-$ nicípios é que tal diminuição dos recursos da saúde poderá refletir-se em novas pressões sobre as finanças municipais, dado que as prefeituras são as executoras da assistência à saúde.

O segundo ponto refere-se à previsão de lei complementar para legislar sobre o ISS, no intuito de coibir a guerra fiscal entre os Municípios. Apesar de ser um imposto de competência municipal, a Lei Complementar 116, de 31/7/2003 (federal, naturalmente), anula praticamente todas as normas anteriores de arrecadação e tributação do ISS, a maior fonte de arrecadação tributária própria dos Municípios. Houve, é verdade, uma ampliação significativa dos serviços a serem tributados; no entanto, a alíquota máxima permaneceu fixada em 5\%, sendo que a mínima já estava estabelecida em 2\% desde a entrada em vigor da Emenda 37. Não obstante a legitimidade dos objetivos perseguidos, trata-se de uma afronta à autonomia municipal instituída na Constituição Federal.

Por fim, cabe citar a Emenda 39, de 19/12/2002, que alterou o sistema tributário nacional ao criar a contribuição para o custeio da iluminação pública nos Municípios e Distrito Federal. Essa foi a primeira Emenda Constitucional que atendeu apenas ao interesse dos Municípios, ampliando sua competência tributária, o que lhes propiciará maior autonomia financeira.

A estagnação econômica compromete a capacidade de extração fiscal num contexto em que ocorre significativa elevação da necessidade de refinanciamento público, como sucedeu durante o governo Cardoso, aumentando a vulnerabilidade externa do país 
e, assim, dificultando a possibilidade de crescimento econômico. O Produto Interno Bruto (PIB) per capita cresceu apenas 4.73\% durante o primeiro quadriênio da gestão Cardoso (1994-1998), diminuindo ainda mais no segundo quadriênio (1998-2002), quando foi de apenas $2.71 \% .^{12}$ Apesar desse desempenho ruim, a carga tributária global, que era de $29.8 \%$ do РІв, em 1994, elevou-se para 35.6\%, em 2002. E, apesar dessa ampliação, as receitas partilháveis com os âmbitos subnacionais de governo pouco ou nada se elevaram, suscitando uma fragilidade na estrutura federativa pactuada em 1988. Não causa surpresa, assim, que os Municípios tenham sido atendidos, finalmente, ainda que apenas nos últimos dias do governo Cardoso, pela entrada em vigor de um novo tributo de competência municipal.

Cabe considerar, entretanto, que é muito diferente o impacto causado por medidas que possibilitam o aumento da arrecadação própria municipal, como é o caso do IPTU progressivo, do causado por medidas que elevam as receitas de transferências. Estas últimas, para cerca de 85\% dos Municípios brasileiros, com população inferior a 30 mil habitantes, são as que têm maior impacto nas suas receitas municipais. Medidas que aumentam o potencial de arrecadação própria provocam maior impacto apenas entre os Municípios com base econômica mais significativa. É o caso dos 223 Municípios brasileiros cuja população supera os 100 mil habitantes, mas, em particular, dos maiores, capitais estaduais ou com população superior a 300 mil habitantes. ${ }^{13}$ Nessas condições, à grande maioria desses Municípios brasileiros interessam medidas que resultem em aumento das transferências, mesmo que sejam transferências voluntárias, como são os convênios, além do sus e do Fundef. Aos Municípios de maior porte, importa ampliar a sua competência tributária. Nunca é demais lembrar que ao conjunto dos Municípios a medida de maior impacto nas suas receitas e, portanto, na sua autonomia financeira, seria a retomada do crescimento, pois isso significaria elevação da quota-parte do Impuesto a la Circulación de Mercaderías y Servicios (ICMS), a principal fonte de receitas dos Municípios.

Todo esse cenário que aqui se tentou delinear, de verdadeira "queda de braço" entre os entes federativos - cujos atores principais têm sido o Município, de um lado, como "perdedor", e a

\footnotetext{
${ }^{12}$ Evolução do PIB per capita, a preços constantes de 2002, segundo a base de dados do Ipea/Ministério do Planejamento: Ipeadata.

${ }^{13}$ Existe uma relação positiva entre tamanho da população municipal e arrecadação tributária própria dos Municípios. Essa relação está apontada em Penalva Santos (2003a).
} 
União, de outro, como recorrente "ganhadora" -, teve um epílogo retumbante logo no início do governo Lula, em 2003, com o início dos debates sobre a nova proposta de Reforma Tributária.

A proposta foi aprovada no Congresso Nacional, mas, ao chegar no Senado, foi modificada, tendo reduzido seu escopo. Estabeleceram-se três etapas de discussão. A primeira foi aprovada e instituída pela Emenda Constitucional n. 42, de 19/12/2003, e seguiu a orientação do governo Cardoso: os principais pontos referem-se à CPMF, que se transforma em contribuição em caráter permanente, à DRU, que também se torna permanente; mas, diferentemente do que vigia ao tempo de Cardoso, a CIDE deve ser partilhada com os Estados e Municípios. A dificuldade de atender governadores de uma Federação tão economicamente desequilibrada como a nossa postergou para uma outra etapa da reforma a unificação da legislação do ICMS, o principal imposto no sistema tributário brasileiro.

No que tange aos Municípios especificamente, os ganhos referem-se à participação na arrecadação da CIDE, mas está aberta a possibilidade de sair da Constituição o critério de partilha das receitas de transferência do ICMS nas etapas seguintes da reforma. Hoje, os $25 \%$ da arrecadação do ICMS são distribuídos, numa proporção de $80 \%$, de acordo com o que é arrecadado em cada Município, o que beneficia os Municípios de melhor base econômica. Uma alteração nesse critério poderá beneficiar os Municípios economicamente menos dinâmicos, atendendo ao interesse da maioria deles, contudo afetará as receitas municipais dos maiores, justamente os que sofrem maiores pressões demográficas. As transferências do ICMS, ao contrário das do FPM, não têm um viés redistributivista, mas isso poderá ser alterado na reforma tributária em discussão. Cabe frisar que a quota-parte do ICMS representa a maior fonte de receitas municipais considerando o conjunto dos Municípios. Trata-se, portanto, de uma possível alteração de grande monta nas receitas e, portanto, na autonomia financeira dos Municípios.

\section{Considerações finais}

À guisa de conclusão, pode-se afirmar que não há como o Município exercer sua autonomia - ou exercer, com plenitude, a sua condição de ente da Federação -, se a sua autonomia financeira não for uma conquista permanente. 
Diante da já mencionada "sanha fiscal" da União, o Município não pode utilizar, como bem entender e achar conveniente, o que o constituinte disse que lhe pertencia de direito: os recursos financeiros provenientes das transferências constitucionais, que vêm sendo cada vez mais contingenciadas.

A par disso, o Município vem assumindo despesas que deveriam ser arcadas pela União e pelos próprios Estados-Membros. Um estudo do Instituto Brasileiro de Administração Municipal (IBAM) (Bremaeker, 2003) aponta para valores correspondentes, no ano de 1998, a 4.52\%, das receitas municipais comprometidas com aquelas despesas, que incluem, entre outras, a manutenção do Fórum e os serviços da Justiça Eleitoral e dos cartórios.

Com isso, enfraquece-se o Município e se desestrutura o equilíbrio de forças que deveria existir entre os entes da Federação.

O enfraquecimento dos Municípios, entretanto, é percebido com preocupação pelo mesmo presidente Cardoso, cujo governo patrocinou substancial reforma do Estado que resultou numa estrutura federativa tão distante da imaginada pelo constituinte de $1988 .{ }^{14}$ Ao completarem-se os 15 anos da promulgação da Constituição, Cardoso declarou ser favorável à realização de uma “miniconstituinte" (Folha de S. Paulo, 2003), isto é, uma revisão constitucional de parte da Carta Magna, o que incluiria apenas as questões relativas à Previdência, ao Sistema Tributário e ao Pacto Federativo. Reconhecia, assim, que sob seu governo não conseguira estabelecer bases sustentáveis para a estrutura federativa em vigor. No entanto, sob seu governo, essa fora alterada, quase sempre em favor da União, indicando que o governo fora movido pelas circunstâncias que o levaram a ajustar suas finanças em detrimento do ente mais frágil da Federação, o Município.

O governo que o sucedeu, do presidente Lula (2002-2006), elegeu-se com um discurso de oposição, comprometendo-se com as teses progressistas, as quais incluíam o fortalecimento dos governos municipais. O êxito de alguns desses governos, sob a administração do PT, o partido de Lula, sustentava o compromis-

${ }^{14}$ Além das Emendas à Constituição Federal, o governo Cardoso promulgou duas leis muito importantes para os Municípios: a Lei de Responsabilidade Fiscal e o Estatuto da Cidade. A primeira estabelece normas de controle dos entes governamentais, visando sobretudo aos governos municipais, mais difíceis de serem controlados, dada a enorme capilaridade da malha urbana brasileira, constituída de 5,561 Municípios. A segunda, o Estatuto da Cidade, é a lei que regulamenta os arts. 182 e 183 da Constituição Federal, permitindo que os Municípios utilizem os novos instrumentos jurídicos de controle do uso do solo criados em 1988, dentre os quais a cobrança do IPTU progressivo e a outorga onerosa dos direitos de construir. 
so do novo governo com a descentralização das políticas públicas. A criação do Ministério das Cidades, uma novidade na estrutura administrativa, sinalizava na mesma direção. No entanto, o governo Lula só tomou iniciativas de propor alterações na Constituição Federal naqueles pontos já indicados por Cardoso: nas questões previdenciária e tributária. A primeira foi aprovada e instituída pela Emenda Constitucional 41, de 19/12/2003, enquanto a segunda, que interfere de modo mais direto no Pacto Federativo, não conseguiu as condições políticas necessárias para ser aprovada na íntegra, segundo o projeto apresentado pelo governo, sendo dividida em etapas, das quais aprovou-se apenas a primeira. Isso, entretanto, está menos relacionado ao fato de os Municípios terem sido pouco ouvidos e mais à falta de acordo entre os governadores.

Não se desconhece a enorme diversidade econômica, social, política e demográfica entre os 5,561 Municípios brasileiros. Essa diversidade dificulta a participação dos Municípios nas discussões sobre reforma tributária, já que são muito distintos os interesses dos de pequeno porte em relação aos maiores, por exemplo. No entanto, a participação dos Municípios nas reformas institucionais seria viabilizada mediante as organizações representativas dos Municípios de pequeno porte - 90\% deles têm população inferior a 50 mil habitantes - e das capitais estaduais, já organizados e representados, respectivamente, pela Confederação Nacional dos Municípios (CNM) e pela Associação Brasileira das Prefeituras das Capitais. Os Municípios de médio porte acabam por estar mal representados pela CNM, mas, pelo seu pequeno número, podem ser representados por deputados, embora isso não deva substituir uma organização como as das duas classes de cidades mencionadas.

Assim, apesar de um aparato institucional que sustenta a posição de ente da Federação aos Municípios e dos avanços no governo Lula a respeito da importância dos governos municipais, o Município permanece um ente federativo de segunda classe.

\section{Bibliografia}

BNDES (Área de Planejamento - Departamento Econômico) (2003), Boletim Informe-se, n. 54, abril (Carga Tributária Global. Estimativa para 2002). 
Bonavides, Paulo (1997), Ciência Política, Malheiros, São Paulo.

Bremaeker, François (2003), Despesas municipais com as funções de competência da União e dos Estados em 2001, IBAM, Série Estudos Especiais, n. 49, maio, Rio de Janeiro.

Folha de S. Paulo (2003), jornal de circulação no Brasil, 5 out.

Kugelmas, Eduardo (2001), "A evolução recente do regime federativo no Brasil", in Wilhelm Hofmeister e José Mário Brasiliense Carneiro (orgs.), Federalismo na Alemanha e no Brasil, Fundação Konrad Adenauer, Série Debates, v. I, n. 22, abril, São Paulo.

Lira, Ricardo (1996), Elementos de Direito Urbanístico, Renovar, Rio de Janeiro.

Melo, Marcus André (2002), Reformas Constitucionais no Brasil: instituições políticas e processo decisório, Revan, Rio de Janeiro; Ministério da Cultura, Brasília.

Penalva Santos, Angela Moulin (2003a), "Reforma do Estado, descentralização e autonomia financeira dos Municípios”, Revista de Administração do Mackenzie - RAM, ano 4, v. 2, São Paulo.

Vedana, Celso (2002), Federalismo: Autonomia Tributária Formal dos Municípios, Habitus, Florianópolis.

Recibido: 4 de julio de 2005. Aceptado: 5 de septiembre de 2005.

Angela Moulin S. Penalva Santos. Economista (Universidad del Estado del Río de Janeiro, UERJ), maestra en ingeniería de la producción (COPPE/UFRJ) y doctora en estructuras ambientales urbanas (FAU/USP). Profesora adjunta de la UERJ, en la Facultad de Ciencias Económicas y en el Programa de Posgrado en Derecho desde 1981 (asignaturas: Planeación Urbana, Estado y Políticas Públicas, Economía Política, Economía Fluminense y Formación Económica de Brasil). Investigadora del Conselho Nacional de Desenvolvimento Científico e Tecnológico; líneas de investigación: 
federalismo fiscal, descentralización, ciudades medianas y economía fluminense. Profesora visitante del Programa de Maestría en Desarrollo Regional y Gestión de Ciudades de la Universidad Cândido Mendes (UCAM) desde 2001. Autora de Economia, Espaço e Sociedade no Rio de Janeiro, FGV, Río de Janeiro, 2003; de dos capítulos (en coautoría) del libro Cidades Médias Brasileira, IPEA, Río de Janeiro, 2001 ("Fluxos migratórios nas cidades médias e regiões metropolitanas", pp. 171-212, y "Federalismo no Brasil: análise da descentralização financeira da perspectiva das cidades médias”, pp. 295-336); así como de varios artículos en revistas, como "Descentralização e autonomia financeira municipal: a perspectiva das cidades médias", Indicadores Econômicos, FEE/RS, 32 (3): 101-126, y, en coautoría, el "bota-abaixo revisitado: o Executivo municipal e as reformas urbanas no Rio de Janeiro (1903-2003)", Revista Rio de Janeiro, mayo-agosto 2003, núm. 10: 11-34.

Liana Portilho Mattos es abogada (UFMG), especialista en análisis urbano (UFMG) y maestra en derecho de la ciudad (UERJ); procuradora del estado de Minas Gerais y profesora de la Pontifícia Universidade Católica de Minas Gerais (PUC/MG), donde coordina los cursos de actualización y especialización a distancia en el área de derecho. También es profesora de cursos de posgrado lato sensu (asignaturas: Derecho Urbanístico, Estatuto de la Ciudad y Legislación Urbanística y Ambiental) en el Centro de Actualización en Derecho, CAD/Gama Filho, en el Instituto de Educación Continuada (IEC/PUC Minas) y en el pUC Minas Virtual. Es miembro del International Research Group on Law and Urban Space (IRGLUS), grupo de trabajo afiliado al Research Committee on Sociology of Law of the International Sociological Association (RCSL) desde 1997, y del Instituto Brasileño de Derecho Urbanístico (IBDU) desde 2001. Es autora del libro A efetividade da função social da propriedade urbana à luz do estatuto da cidade, Temas \& Idéias, Río de Janeiro, 2003; organizadora y coautora de Estatuto da Cidade Comentado, Mandamentos, Belo Horizonte, 2002, y de varios artículos y capítulos en revistas y libros, como "A simplificação do direito e o acesso à justiça" en la Revista de Direito da Associação dos Procuradores do Novo Estado do Rio de Janeiro, en Gustavo Binenbojn (coord.) Direitos Fundamentais, vol. XII, Lumen Juris-APERJ (Associação dos Procuradores do Novo Estado do Rio de Janeiro), 2003, Río de Janeiro, pp. 333-343; "Viver, morar, transitar: o homem e a cidade", en Cár- 
men Lúcia Antunes Rocha (coord.), O direito à vida digna, Fórum, Belo Horizonte, 2004, pp. 289-316; “Concessão de uso especial para fins de moradia: um caso concreto", en Betania Alfonsin y Edésio Fernandes (orgs.), Direito à moradia e segurança da posse no estatuto da cidade: diretrizes, instrumentos e processos de gestão, Fórum, Belo Horizonte, 2004, pp. 179-201. 